\title{
PROCESSO ADMINISTRATIVO DE TRÂNSITO DO ESTADO DE SÃO PAULO: DA AUTUAÇÃO A CASSAÇÃO DO DIREITO DE DIRIGIR
}

\author{
Fabíola Soares de Melo
}

Universidade do Oeste Paulista - UNOESTE, curso de Direito, Presidente Prudente, SP. E-mail:

fabiola.fah.melo@hotmail.com

\section{RESUMO}

O objetivo deste estudo foi compreender o que é o processo administrativo de trânsito focando em seu funcionamento no Estado de São Paulo. Partindo de conceitos básicos, por exemplo, quais são as multas que geram suspensão, e o processo respectivo, que pode levar a cassação, visitou-se o sistema pontuação, para saber exatamente qual a finalidade última de tais medidas, dentre outros pontos. A pesquisa exploratória e bibliográfica utilizou o método dedutivo, ou seja, do geral (desde uma simples multa) para o particular (desvendar como se chega a pior penalidade de trânsito: a cassação da habilitação ou direito de dirigir). A conclusão do trabalho foi a de que tais processos de aplicação de penalidade se dividem dentro da esfera administrativa, no que se convencionou denominar de instâncias administrativas e, embora adquirindo um aspecto judicial, continuam restritos ao executivo ou seara administrativa. Não obstante tais decisões podem ser levadas ao âmbito judicial.

Palavras-chave: administrativo, trânsito, multa, suspensão, cassação.

\section{ADMINISTRATIVE PROCESS OF TRANSIT OF THE STATE OF SÃO PAULO: OF THE AUTO UNTIL THE FOUNDATION OF THE RIGHT TO DRIVE}

\begin{abstract}
The objective of this study was to understand what is the administrative traffic process focusing on its operation in the State of São Paulo. Starting from basic concepts, for example, which are the fines that cause suspension, and the respective process, which may lead to cassation, the punctuation system was visited, to know exactly what the ultimate purpose of such measures, among other points. The exploratory and bibliographical research used the deductive method, that is, from the general (from a simple fine) to the particular one (to unmask as if it arrives the worse traffic penalty: the cassation of the habilitation or right to direct). The conclusion of the work was that these procedures for the application of penalty are divided within the administrative sphere, in what is known as administrative instances and, although acquiring a judicial aspect, are still restricted to the executive or administrative court. Notwithstanding such decisions can be taken to the judicial scope.
\end{abstract}

Keywords: Administrative, transit, fine, suspension, cassation.

\section{INTRODUÇÃO}

Segundo o dicionário a palavra trânsito significa: passagem, trajeto, o movimento de pedestres e veículos que transitam nas cidades ou nas estradas. Por possuir significado de passagem existe trânsito em todos os lugares do globo, inclusive nos mais remotos.

Pode-se datar o surgimento do trânsito a partir dos primeiros aglomerados de pessoas. Porém, apenas com o surgimento das primeiras cidades, surgiram os primeiros problemas que passaram a interessar o Direito pois, com os conflitos que ultrapassaram a esfera individual exigiu- 
se o regramento e sua violação um imperativo, principalmente quando os conflitos exigiram alguma solução jurídica para a organização do trânsito e pouco mais tarde a segurança.

Como solução foram criadas as Leis de Trânsito, que variam de cidade pra cidade e se modificam, ao longo do tempo, para suprir as lacunas existentes, visando a segurança e bem estar de todos.

Um bom exemplo dentro do nosso Código de Trânsito Brasileiro é a obrigatoriedade do uso do capacete para motociclistas e o aumento das multas e fiscalização. É sabido que nos anos 70 e 80 já existiam leis acerca do tema, mas de certa forma não obrigava (ou se fazia vista grossas) e não se aplicavam penas graves.

O assunto é, pois, de interesse fundamental para todos que se utilizam deste meio de transporte, bem como para os que se interessam pela atuação jurídica nesta especialização.

\section{METODOLOGIA}

A metodologia realizada neste trabalho orienta-se pelo método hipotético-dedutivo, possuindo como fontes e material de pesquisa as lei, as resoluções, a doutrina e a jurisprudência.

\section{DISCUSSÃO}

O Código de Trânsito atual entrou em vigor em 22 de janeiro de 1998 com a Lei $n^{\circ} 9.508$ de 23 de setembro de 1997 e, desde tal data visa, principalmente, propiciar a segurança nas vias públicas e de seus usuários. Para tal o código viabilizou um procedimento administrativo ao alcance de todos, uma vez que não se precisa da capacidade postulatória especial por meio de advogados (muito embora possa em alguns casos ser indispensável para o sucesso da defesa de quem recorre). O usuário pode recorrer de multas ou de procedimentos administrativos que envolvam suspensão ou cassação tem legitimidade, independente de advogado. Terceiros exceto procuradores não possuem legitimidade.

Não obstante, como se adiantou, deve-se levar em consideração que a experiência, conhecimento da lei e linguajar mais objetivo do advogado pode gerar mais uma chance para uma decisão positiva. Uma simples leitura das penalidades pode ser difícil para um leigo. Por exemplo, vale a pena transcrever a lição do doutrinar com as simples menção do próprio texto da lei, que pode ser difícil para um infrator que não tenha conhecimento técnico jurídico: "As penalidades que tem seu processo administrativo previsto nas resoluções do CONTRAN são as seguintes: multa, advertência por escrito, suspensão do direito de dirigir e cassação do documento de habilitação", (MACEDO, Leandro, 2013).

Não bastasse a linguagem técnica, durante sua vigência ocorreram várias adequações às necessidades da sociedade. Sempre com intuito de evitar qualquer tipo de acidentes. Uma das principais adequações e especificadamente aplicada aos motociclistas foi a obrigatoriedade do uso do capacete para o condutor e passageiro (art. 244, incisos I e II do CTB). Inclui-se, também, a tipificação da embriaguez como crime de trânsito em 2008 (art. 165 do CTB).

O valor da multa, que é gerado com a infração, atualiza-se anualmente e tais valores são fixos durante sua vigência. Pode haver agravantes do valor da multa que dependem do enquadramento legal, daí a importância de os usuários terem boas noções sobre a legislação de trânsito e sua atualização.

Uma vez encaminhada para o prontuário, que é uma espécie de banco de dados de todos os que possuem a Carteira Nacional de Habilitação $(\mathrm{CNH})$, esta pontuação é somada e se ultrapassar o somatório 20 pontos no período de 12 meses ocorre a instauração de uma portaria. Uma vez gerada pode-se recorrer ou cumprir. Cumprir significa que o condutor ficará um período de tempo com o direito de dirigir suspenso e após esse período deverá concluir curso de reciclagem de condutores. Eis a lei nesse aspecto: 
259. CTB. A cada infração cometida são computados os seguintes números de pontos:

I - gravíssima - sete pontos;

II - grave - cinco pontos;

III - média - quatro pontos;

IV - leve - três pontos.

Com a Lei no 13.281 de 4 de maio de 2016, que alterou o art. 261 do CTB, houve uma mudança mais radical no que diz respeito ao tempo de suspensão do direito de dirigir, pois anteriormente era de no mínimo 1 mês, passando para 6 meses, e no caso de reincidência 8 meses.

Durante o período de suspensão se o habilitado não cumprir a suspensão e for autuado dirigindo, gera-se uma cassação. A cassação, por sua vez, é a perda do direito de dirigir por dois anos e após esse período se reabilitar.

No que diz respeito a fiscalização e esfera de competência, cada município possui um órgão municipal incumbido da fiscalização e controle do trânsito. A entidade encarregada de controlar a parte administrativa em nível estadual é o DETRAN (Departamento Estadual de Trânsito).

Conforme Leandro Macedo (2013, pg. 73/74) conceitua, o órgão DETRAN juridicamente tem conceito múltiplo e age em parceria com outros entes estatais, cabendo a ele algumas atribuições que vale a pena destacar:

"Poderíamos conceituar o DETRAN como o órgão de trânsito que atua em áreas urbanas, divide suas atribuições com os órgãos executivos de trânsito municipais e tem como atribuições principais: realizar, fiscalizar e controlar o processo de formação, aperfeiçoamento, reciclagem e suspensão de condutores, expedir e cassar licença de aprendizagem, permissão para dirigir e carteira nacional de habilitação, mediante delegação do órgão federal competente, dentre muitas outras atribuições, que veremos adiante.

O DETRAN também tem a atribuição de vistoriar, inspecionar quanto às condições de segurança veicular, registrar, emplacar, selar a placa, e licenciar veículos, expedindo o Certificado de Registro e o Licenciamento Anual, mediante delegação do órgão federal competente."

Partindo do conhecimento de como são as competências e a quem cabe fiscalizar o trânsito, importante um breve estudo de como se procedem as várias formas de autuação dos infratores. Elas podem ser eletrônicas, como por exemplo as geradas quando se passa em alta velocidade em um radar, ou físicas (via papel), não sendo obrigatória a entrega de canhoto para a existência da multa. $O$ dispositivo legal abaixo é auto explicativo:

Art. 280.CTB. Ocorrendo infração prevista na legislação de trânsito, lavrarse-á auto de infração, do qual constará:

I - tipificação da infração;

II - local, data e hora do cometimento da infração;

III - caracteres da placa de identificação do veículo, sua marca e espécie, e outros elementos julgados necessários à sua identificação;

IV - o prontuário do condutor, sempre que possível;

$V$ - identificação do órgão ou entidade e da autoridade ou agente autuador ou equipamento que comprovar a infração; 
VI - assinatura do infrator, sempre que possível, valendo esta como notificação do cometimento da infração.

Muitos cidadãos esquecem, ou simplesmente não tem tempo, e ai entra a atuação do advogado, pois uma simples multa pode ser objeto de recurso. O recurso seguirá os trâmites do processo administrativo e possui três instâncias administrativas para recorrer: DETRAN, JARI e CETRAN (as duas últimas no caso de indeferimento).

Primeiro passo quando se analisa uma multa, é observar se ela está atendendo todos os aspectos que a lei especifica, pois, podem ocorrer erros nas placas ou no enquadramento por exemplo. No caso da multa via eletrônica que existe a foto do veículo, observar se é realmente o veículo, porque há casos de clonagem de placas ou o sistema pode ter gerado a multa errada.

A multa é uma sanção, por isso ela pode ser defendida. Dentro do prazo estipulado podese apresentar defesas e recursos. A principal delas é a indicação do real condutor no caso de multas que não ocorreram a autuação do condutor (multas impróprias). Todavia se for uma multa de responsabilidade do proprietário não há a possibilidade da transferência (responsabilidade própria), Nestes casos pode-se se falar que a multa pertence ao automóvel, sem a apresentação do condutor ela automaticamente vai ao proprietário.

Art. 257.CTB. As penalidades serão impostas ao condutor, ao proprietário do veículo, ao embarcador e ao transportador, salvo os casos de descumprimento de obrigações e deveres impostos a pessoas físicas ou jurídicas expressamente mencionados neste Código.

$\S 1$ 을 Aos proprietários e condutores de veículos serão impostas concomitantemente as penalidades de que trata este Código toda vez que houver responsabilidade solidária em infração dos preceitos que thes couber observar, respondendo cada um de per si pela falta em comum que Ihes for atribuída.

$\S 2$ 20 Ao proprietário caberá sempre a responsabilidade pela infração referente à prévia regularização e preenchimento das formalidades e condições exigidas para o trânsito do veículo na via terrestre, conservação e inalterabilidade de suas características, componentes, agregados, habilitação legal e compatível de seus condutores, quando esta for exigida, e outras disposições que deva observar.

$\S$ 3ㅇ Ao condutor caberá a responsabilidade pelas infrações decorrentes de atos praticados na direção do veículo.

$\S 4$ O O embarcador é responsável pela infração relativa ao transporte de carga com excesso de peso nos eixos ou no peso bruto total, quando simultaneamente for o único remetente da carga e o peso declarado na nota fiscal, fatura ou manifesto for inferior àquele aferido.

$\S 5$ ㅇ 0 transportador é o responsável pela infração relativa ao transporte de carga com excesso de peso nos eixos ou quando a carga proveniente de mais de um embarcador ultrapassar o peso bruto total.

$\S 60$ O transportador e o embarcador são solidariamente responsáveis pela infração relativa ao excesso de peso bruto total, se o peso declarado na nota fiscal, fatura ou manifesto for superior ao limite legal.

$\S 7$ o Não sendo imediata a identificação do infrator, o proprietário do veículo terá quinze dias de prazo, após a notificação da autuação, para apresentá-lo, na forma em que dispuser o CONTRAN, ao fim do qual, não o fazendo, será considerado responsável pela infração. 
§ 8으 Após o prazo previsto no parágrafo anterior, não havendo identificação do infrator e sendo o veículo de propriedade de pessoa jurídica, será lavrada nova multa ao proprietário do veículo, mantida a originada pela infração, cujo valor é o da multa multiplicada pelo número de infrações iguais cometidas no período de doze meses.

$\S 9$ o O fato de o infrator ser pessoa jurídica não o exime do disposto no § 3ㅇ do art. 258 e no art. 259.

No caso de pessoa jurídica, se não ocorrer dentro do prazo a identificação do condutor, o valor da multa pode ser dobrado.

$\mathrm{Na}$ petição de recurso é necessário incluir os dados completos do autuado, juntamente com as informações do veículo, fundamentando a tese jurídica da defesa de preferência com jurisprudência e doutrina, expondo o fato e a irregularidade encontrada.

No caso das multas leves e médias, caso dentro de 12 meses não ocorreram outras, podese solicitar a conversão da infração em advertência, nestes casos, ao invés do envio do boleto para pagamento é enviado a advertência, ou seja, não há a necessidade do pagamento, porém, a pontuação entra no prontuário.

Art. 267. CTB. Poderá ser imposta a penalidade de advertência por escrito à infração de natureza leve ou média, passível de ser punida com multa, não sendo reincidente o infrator, na mesma infração, nos últimos doze meses, quando a autoridade, considerando o prontuário do infrator, entender esta providência como mais educativa.

$\S 1$ 10 A aplicação da advertência por escrito não elide o acréscimo do valor da multa prevista no $\S 3$ ㅇ do art. 258 , imposta por infração posteriormente cometida.

Quanto ao prazo para indicação e ou recurso, ele normalmente está estipulados na carta enviada pelo órgão responsável pela autuação. Na ausência, são normalmente trinta dias contados a partir da data da notificação, ou seja, da chegada da carta.

Todo recurso pode ou não ser deferido, depende de circunstâncias como legitimidade, tempestividade, falta de assinaturas entre outros motivos que podem levar ao indeferimento.

Quando a pontuação, existente em cada $\mathrm{CNH}$, a soma de 20 pontos gera uma portaria ou no caso de multas denominadas "auto suspensivas" imediatamente são emitidas as portarias. São exemplos destas ocorrências: dirigir embriagado (art. 306 do CTB); negativa de se submeter ao bafômetro (Lei n.o 13.281/2016); pilotar sem capacete (art. 244, I CTB); passageiro da motocicleta sem capacete (art. 244, II CTB), carregar menores de sete anos na motocicleta (art. 244, V CTB); pilotar motocicleta com os faróis apagados (art. 244, IV CTB); apostar os chamados "rachas" (art. 308 CTB); dirigir ameaçando pedestres ou demais veículos (art. 170 CTB); fazer manobras perigosas (arts. 244, III e 175 CTB); deixar de prestar socorro no caso de acidentes (art. 304 CTB); transpor bloqueio policial (art. 210 CTB); e ou dirigir acima de 50\% da velocidade permitida (art. 218 CTB). Qualquer dessas ocorrências, após emissão dessas portarias e após transitar em julgado, levam a suspensão do direito de dirigir.

Por outro lado, passadas as noções de como o processo administrativo caminha, é interessante destacar os efeitos da temida pena de suspensão. Segundo José Almeida Sobrinho (2012, pg. 256) a suspensão é:

"Mais restritiva do que a pena de multa, a suspensão do direito de dirigir atinge diretamente o condutor habilitado, restringindo-Ihe a liberdade ao vedar temporariamente uma prática para a qual está habilitado. É um tipo 
de punição restritiva, que se prolonga no tempo e que impõe um comportamento pessoal, tendo efeito mais constrangedor do que a pena de multa."

Esta penalidade gera a necessidade do curso de reciclagem de condutores, pois sem o certificado de cumprimento do curso o Detran não autoriza o condutor a voltar a dirigir.

No caso das permissões para dirigir (PPD), não há suspensão. Existindo nesse período (quando o condutor ainda está no primeiro ano de sua habilitação) no caso de infrações graves, gravíssimas ou reincidência de infrações médias, perde-se o direito de dirigir e torna-se necessário todo o procedimento como se fosse uma nova habilitação (reabilitação). Quanto a defesa, não há recurso a JARI ou CETRAN, apenas DETRAN.

Quando se recebe a carta da instauração da portaria, pode-se recorrer ou cumprir, o tempo de suspensão varia dependendo da multa, reincidência, entre outros motivos que podem aumentar o período. O processo administrativo de trânsito, em regra, é rápido, podendo ser feito via eletrônica, mas há casos que demoram meses

Eis o que prevê a legislação em comento:

Art. 261. CTB. A penalidade de suspensão do direito de dirigir será imposta nos seguintes casos:

I - sempre que o infrator atingir a contagem de 20 (vinte) pontos, no período de 12 (doze) meses, conforme a pontuação prevista no art. 259; II - por transgressão às normas estabelecidas neste Código, cujas infrações preveem, de forma específica, a penalidade de suspensão do direito de dirigir.

o Os prazos para aplicação da penalidade de suspensão do direito de dirigir são os seguintes:

I - no caso do inciso I do caput: de 6 (seis) meses a 1 (um) ano e, no caso de reincidência no período de 12 (doze) meses, de 8 (oito) meses a 2 (dois) anos;

II - no caso do inciso II do caput: de 2 (dois) a 8 (oito) meses, exceto para as infrações com prazo descrito no dispositivo infracional, e, no caso de reincidência no período de 12 (doze) meses, de 8 (oito) a 18 (dezoito) meses, respeitado o disposto no inciso II do art. 263.

A cassação é pena mais grave do que a suspensão e resulta na perda do direito de dirigir por dois anos e sujeita o infrator a necessidade de reabilitação, tal pena ocorre quando do não cumprimento da suspensão.

Todas penas impostas são voltadas a prevenir novas infrações, por isso a necessidade de reabilitação ou curso de reciclagem. Contudo, a legislação não pode estar restrita à esfera administrativa e caberá ao cidadão inteirar-se de seus direitos e a possibilidade de esgotar, também a via judicial, por meio do Mandado de Segurança, remédio processual para salvaguardar direito líquido e certo contra ato coator de autoridade.

\section{CONCLUSÃO}

O Código de Trânsito visa não só a proteção das boas prática e conduta no trânsito evitando acidentes e permitindo a segurança no trânsito. São leis essenciais para a preservação da vida na complexa malha viária brasileira. As sanções são a forma de exteriorizar tal proteção.

Contudo, toda ação administrativa possui o direito sagrado ao direito de defesa via recurso administrativo ou judicial mas nem todos os cidadãos estão aptos tecnicamente a exercer esse direito. Devem saber que mesmo após o trânsito em julgado (na via administrativa) ainda há a 
possibilidade da busca do deferimento e absolvição de penas impostas na via judicial por meio do denominado remédio constitucional: mandado de segurança, ainda que até a conclusão judicial e eventual decisão favorável dessa via a pena imposta pela via administrativa será válida.

O DETRAN e outros órgãos administrativos são necessários para manter a ordem e segurança no trânsito, tendo em vista, que se não existisse essas leis, ocorreriam perdas inumeráveis de vidas. Explorar essa área para o operador do direito é um nicho lucrativo, pois é possível cobrar honorários advocatícios independente do resultado. Não bastasse após os recursos administrativos o "cliente" insatisfeito com a decisão administrativa ainda terá como consolo e é permitido que se busque o judiciário, onde poderão ser cobrados novos honorários com a possibilidade de um valor maior no caso da resposta favorável.

O direito abre diferentes áreas promissoras e sem dúvida alguma o processo administrativo e ou judicial (se for o caso) atreladas às infrações de trânsito, é uma delas.

\section{REFERÊNCIAS}

MACEDO, Leandro. Legislação de Trânsito para Concursos, 2ª edição, Método, São Paulo, 2013.

GAMA, Ricardo Rodrigues. Como fazer recursos de trânsito, 2a edição, Russell Editores, Campinas/SP, 2003.

MARRONE, José Marcos. Direito de trânsito: aspectos penais e processuais do Código de Trânsito Brasileiro: Lei n.o 9.503/97, Atlas, São Paulo, 1998.

RIZZARDO, Arnaldo. Comentários ao Código de Trânsito Brasileiro, 5a edição, Editora Revista dos Tribunais, São Paulo, 2004.

BRASIL. Código de Trânsito Brasileiro. Organização de Anne Joyce Angher. 18a edição. São Paulo: Rideel, 2014.

MELHORAMENTOS. Dicionário de língua portuguesa, 2004.

ALMEIDA SOBRINHO, José. Comentário ao Código de Trânsito Brasileiro, 1ํe edição, Editora Forense, Rio de Janeiro, 2012. 